Ingrid Gilcher-Holtey und Eva Oberloskamp (Hrsg.)

Warten auf Godot? 


\section{Schriftenreihe der Vierteljahrshefte für Zeitgeschichte}

Im Auftrag des

Instituts für Zeitgeschichte München-Berlin herausgegeben von

Helmut Altrichter, Horst Möller, Margit Szöllösi-Janze und Andreas Wirsching

Redaktion:

Johannes Hürter und Thomas Raithel

\section{Band 120}




\section{Warten auf Godot?}

Intellektuelle seit den 1960er Jahren

Herausgegeben von

Ingrid Gilcher-Holtey und Eva Oberloskamp

OLDENBOURG 
ISBN 978-3-11-068140-6

e-ISBN (PDF) 978-3-11-068144-4

e-ISBN (EPUB) 978-3-11-068149-9

ISSN 0506-9408

Library of Congress Control Number: 2020941461

Bibliografische Information der Deutschen Nationalbibliothek

Die Deutsche Nationalbibliothek verzeichnet diese Publikation in der Deutschen Nationalbibliografie; detaillierte bibliografische Daten sind im Internet über http://dnb.dnb.de abrufbar.

(C) 2020 Walter de Gruyter GmbH, Berlin/Boston

Titelbild: Naomi Klein protestiert am 28.6.2010 gegen das Vorgehen der Polizei während eines G20-Gipfeltreffens in Toronto. Foto: Lucas Oleniuk/Toronto Star via Getty Images

Satz: bsix information exchange $\mathrm{GmbH}$, Braunschweig

Druck und Bindung: CPI books GmbH, Leck

www.degruyter.com 